A. V. Borisov

\title{
Numerical integration of differential dynamical equations. Vortex dynamics applications
}

Vestnik Udmurtskogo Universiteta. Matematika. Mekhanika. Komp'yuternye Nauki, 2008, вып. 1, 127-132

\section{References}

[1] Bogomolov V.A., "Dinamika zavikhrennosti na sfere", Izv. AN. SSSR. Mekh. zhid. i gaza, 1977, no. 6, 57-65 MathsciNet Zentral/MATH

[2] Borisov A. V., Mamaev I. S., "Matematicheskie metody dinamiki vikhrevykh struktur", V sb. Fundamentalnye i prikladnye problemy teorii vikhrei, eds. Borisov A. V., Mamaev I. S., Sokolovskii M. A., NITs RKhD, 2003, 704 pp.

[3] Borisov A.V., Mamaev I.S., Puassonovy struktury $i$ algebry Li v gamiltonovoi mekhanike, Izd. dom. "Udmurtskii universitet", Izhevsk, 1999, 464 pp. MathSaiNot Zentrall MATH

[4] Ziglin S. L., "Neintegriruemost zadachi o dvizhenie chetyrekh tochechnykh vikhrei", DAN SSSR, 250:6 (1979), 1296-1300 Math-NetRu MathSeiNet

[5] Kozlov V.V., Simmetrii, topologiya $i$ rezonansy $v$ gamiltonovoi mekhanike, Izd-vo UdGU, Izhevsk, 1995 Mathscilinet Zentral|WATH

[6] Uintner A., Analiticheskie osnovy nebesnoi mekhaniki, Nauka, M., 1967

[7] Sharle K. L., Nebesnaya mekhanika, Nauka, M., 1966, 627 pp. Mathseinet

[8] Aref H., Pomphrey N., "Integrable and chaotic motions of four vortices. I. The case of identical vortices", Proc. R. Soc. London A, 380 (1982), 359-387 dol Mathseinet Zentral MÄTH $a d s^{*}$

[9] Bolsinov A. V., Borisov A. V., Mamaev I. S., "Lie algebras in vortex dynamics and celestial mechanics IV", Reg. \& Chaot. Dyn., 4:1 (1999), 23-50 doi MathscilNot Zentral MÄ̈H

[10] Eckhardt B., "Integrable four vortex motion", Phys. Fluids, 31:10 (1988), 2796-2801 doi MathsciNet ZentralMATH ads" WEB OF SCIENCETM

[11] Khanin K. M., "Quasi-periodic motions of vortex systems", Physica D, 4 (1982), 261269 doi Mathscillet Zentral MATH ads*

[12] Lim C.C., "A combinatorical perturbation method and Arnold's wiskered tori in vortex dynamics", Physica D, 64 (1993), 163-184 doi MathsciNet Zentral|MÄH ads"

[13] Lim C. C., "Graph theory and special class of symplectic transformations: the generalized Jacobi variables", J. Math. Phys., 32:1 (1991), 1-7 dol MathsciNet ZentralMÄH ads* WEB OF SCIENCETM

[14] Newton P.K., The N-Vortex problem. Analytical Techniques, Springer, 2001 Mathsoindet 